Thomas DILLINGER

\section{Facing suburbanisation in the area of Bratislava \\ The border between Austria and the Slovak Republic}

\section{Introduction}

I was born in Vienna. When I was a child, Munich $(400 \mathrm{~km}$ from Vienna) or Venice (720 km from Vienna) appeared closer to me then Bratislava (60 $\mathrm{km}$ from Vienna).

\subsection{Historical review}

This article is based on the results of a research project with was done in the years 2003-2004 in the framework of JORDES+ (Joint Regional Development Strategy) WienBratislava-Györ, co-financed through INTERREG III A.

The working module KOBRA (City-hinterland Co-operation Bratislava) dealt with the border region between Austria and the Slovak Republic in the area of Bratislava, especially the Austrian communities Marchegg, Engelhartstetten, Lassee, Hainburg, Wolfsthal, Berg, Kittsee, Edelstal, Pama and Deutsch Jahrndorf.

One aim of this project was to estimate the interaction potentials and trends between Bratislava and the communities, another to draft the programme approaches for a regional development concept for this agglomeration area.[1]

When talking about suburban development at the AustrianSlovak border we have to keep in mind the history of this area. The new border drawn according to the Peace Treaty from St. Germain after the First World War divided this region between Austria and the Slovak Republic. Especially after the Second World War the building of the Iron Curtain separated - from a historical point of view - formerly structurally strongly related regions. During the time of the Cold War almost no interaction took place between Austria and the Slovak Republic. It was the dead-end of the "West « or if seen from the other side, of the »East«.

With the fall of the Iron Curtain in 1989 slowly, very slowly new developments started in the region. A difficult process started and is still going on. We are faced with specific problems along the border, especially since it is a former iron curtain border:

- The problem of different languages. This is a (perhaps very European) problem, which also exists in other border areas;

- The problem of economic differences, which especially along the former iron curtain, could take a full generation to be diminished;

- The problem of fears and prejudices of people who lived near a closed border for more than 40 years with no or very limited real personal knowledge about the people living on the other side on the border;

- The problem of the »border in the minds " of the people on both sides of a border, which means - especially in the context of the former iron curtain - that their thinking and concerns were for a generation not oriented toward the other side of the border but towards the interior of their own country. Living on a »dead « border created the image of living »on the fringe «, on the periphery. After opening the borders some of these »border-people « were in reality suddenly »in the middle « and confronted with a very difficult (and still ongoing) mental reorientation process.

Austria since 1995 and the Slovak Republic since 2004 are members of the European Union. Still these two countries are divided by the Schengen-border but also this border will disappear in the near future.

\subsection{Regional Framework}

The whole region is dominated by Vienna, as the capital city of Austria, and Bratislava, as the capital city of the Slovak Republic. Vienna and Bratislava together have more than 2 million inhabitants. The agglomeration area ViennaBratislava, including Burgenland, Lower Austria, Vienna and the region Bratislava and Trnava has more than 4,5 million inhabitants.[2]

The region has a big potential for future development. Already in 1993 the importance of this area was stressed in the study The production areas in Western and Eastern Europe (Empirica, Bonn 1993). Bratislava was evaluated to have »the greatest outlook of all regions « surveyed in Europe. [3]

Also in the European context Vienna and Bratislava are labelled as Metropolitan Growth Areas (MEGAs). This typology was the result of an analysis in ESPON 111, i.e. Potentials for polycentric development in Europe, and has identified the strongest urban regions in Europe. [4]

The area between Vienna and Bratislava is still dominated by agriculture. Especially the area north of the Danube, the Marchfeld, is one of the most important agricultural areas in Austria [5]. South of the Danube is the so-called "Arbesthaler Hügeland «, a hilly area with vineyards and forests [6]. Along the Danube lies the National park »Donau-Auen «. All in all, the park is $38 \mathrm{~km}$ long and covers the whole area along the Danube from Vienna up to the Austrian-Slovak border. This National park protects one of the last existing water meadows in central Europe. This water meadow has formed this unique landscape by flooding. In this park we can find very rare fauna and flora. Beside this important National park we can find nature protection areas, Natura 2000 areas and landscape conservation areas.

One of the most discussed issues in the area is the infrastructure connection between Vienna and Bratislava. As a result of the Iron curtain the infrastructure connections from Vienna to the east are very poor. But this infrastructure is seriously needed to develop the whole area.

\section{Road Infrastructure}

There are no motorways between Vienna and Bratislava. In autumn 2004 building of a link began (south of the Danube from Bruck a. d. Leitha to Bratislava), between the existing motorway from Vienna to Budapest (A4). The motorway A6 should be completed in 2007. 
North of the Danube an additional motorway is being discussed. A special survey should find the best corridor for the motorway. Results of the survey are expected in 2005 .

\section{Train infrastructure}

Today there are two direct train connections between Vienna and Bratislava. The fastest connection (Ostbahn) goes south of the Danube. The fastest possible travel time is 46 minutes. The second connection runs north of the Danube (Marchegger Ast). The fastest travel time is 64 minutes. This connection is without electric power and some parts have only a single-track line. To have an efficient connection, this line has to be upgraded.

The oldest train connection between Vienna and Bratislava is the so-called "Pressburger Bahn « (Pressburg is the German name of Bratislava). This connection was built in the Austrian-Hungarian Monarchy. Eight kilometres of this connection are now missing (between Wolfsthal and Bratilslava). This line would be a good connection for linking the region with the cities. [7]

\section{Interaction potentials and trends for the planning area ${ }^{[8]}$}

In the near future the Austrian communities in the area of Bratislava will have the character of Bratislava's suburbs. The aim of these communities has to be to properly prepare themselves for this situation and avoid the main problems of suburbanisation.

This process has to be finished latest when the Slovak Republic signs the Schengen-treaty, because than we have a really open situation. Till this time the communities have to have a clear picture, which part/function they want to play in the Bratislava agglomeration.

The Austrian communities north of the Danube will be affected by this development less than the communities lying southwards. The Danube and the March are still very strong natural barriers. We can aspect that there will be linear development along the main traffic infrastructure.

In the south we will be confronted with a laminar enlargement of Bratislava. Especially the communities lying very close to the city centre of Bratislava (Berg, Wolfsthal and Kittsee) will be affected by this development. Nobody can estimate how quickly this process will proceed. But we can aspect that in future these communities will become one spatial unit with Bratislava.

\subsection{Problems of suburbanisation}

Within this interaction potentials and trends the suburb of Bratislava will be confronted with typical suburban development problems, which we know from other suburb areas. Especially the suburb areas in Austria, which have been "protected « from development because of the »Iron Curtain«, will be faced with these problems.

At this point I will concentrate on the basic problems, which appear in rural communities lying in the hinterland of big cities. The following four illustrate only the most important and frequent problems.

\section{Urban sprawl and uncontrolled land use}

At the borders of city regions in all parts of Europe areas of dispersed land use are growing that are completely dependent on car mobility and without any quality of urban space. This trend cannot be overturned over night. Also in the future the expanding demand for housing land will be determined by one and two-family houses. Because of restructuring in retail we are aware of the continuous tendency towards large and not integrated trade areas. ${ }^{[9]}$

Because of laminar settlement forms, as well as the lack of density at axes, points or knots, the coverage of territory has a high affinity for motorized individual transport. This is further strengthened by the favourable property costs in the suburbs. Traffic relations in the periphery and within the periphery are increasingly also »tangential « (and/or run »circularly«). So far the public local passenger transport has hardly adjusted itself to these traffic needs.

\section{Loss of function - redesigning of the rural area}

The crowding-out effect caused by suburbanisation leads to permanent structural change and to redesign of locations in rural areas. Urban pressures widen to more or less extensive agglomerations and at the same time urban ways of life develop in an intensity that decreases the rural lifestyle in the surroundings. This "redesigning " of former rural area expresses itself both in changes of social structure in the broadest sense and in changes of physiognomy of the communities, which are under such influence. On the other hand this reinforcement of the urban influence is promoted by pull effects of the urban agglomeration: amongst other things the effects shows up in settlements of new commercial enterprises in the closer surrounding area, in strong commuter streams and in larger immigration from more distant areas into the central area and into their neighbouring communities.[10]

\section{Identification problems}

To understand the effects of identification problems better, it is necessary to make a short discourse into the meaning of the word identity. A place in regard to its identity has to be seen as a closed area. Within the municipal borders it shows its own character in a way, that reflects clearly readable characteristics, which makes it recognisable and distinguishable from other places. Identity is what assigns and thus affiliation and gathering occur; it makes a place unmistakable.[11]

Housing Areas, large housing estates and also single-family house areas, are increasingly being pushed into the periphery. In comparison to developed districts with partial mixed use, multi-functionality, »public « and »local identity «, these housing areas have only basic infrastructure. A »decentralized concentration « in the sense of district development is generally missing completely. "Where am I? Everything looks similar. The same shops, the same meal in the restaurants, the same art in the museums, the same films in the cinema. « [12] For the inhabitants this regularity makes it more and more difficult to identify with an unmistakable living area.

\section{Loss of landscape and their distinctness}

With the laminar and scattered development of the city and/or periphery we generally achieve loss of landscape and the recognisability of landscape. As a rule, this loss cannot be compensated with the building of special use areas (e.g. trade areas, housing areas, industrial areas, etc.) This form of building the periphery means at the same time also a dissolving of the recognisability of city borders.[13] 


\section{Conclusion - Programme approaches for a regional development concept for this agglomeration area [14]}

The transformation process has to be seen as a chance The "view « of the Austrian communities in Bratislava's hinterland is still oriented to Vienna. The big chances stemming from the European Union enlargement are not seen in the correct way by these communities or understood in the minds of the local/regional politicians. The communities have to turn around and have to redirect their »view Bratislava. Then they will realise the chances (but also risks) of this new situation.

It must be the aim of the Austrian communities to see this transformation process as a chance. In principal this process enables new development perspectives.

\section{Cultural and ecological qualities have to be put in the} forefront

The cultural and ecological qualities are the most important development requirements, because they will be important economical strengths. The cultural and ecological qualities will in the future become the most important economic factors, when basic infrastructure e.g. traffic infrastructure or high-speed communications lines, have been built, more or less everywhere. The aim is that such a transformation process primarily goes hand in hand with respect and regard for the unique local characteristics and qualities, e. g. cultural heritage and landscape.

\section{Identities have to be developed}

In terms of "decentralised concentration « the communities have to develop identities, which have their own character and are clearly visible from outside. In the future the existing identities of the Austrian communities close to Bratislava will be influenced by it. Especially these communities have to redefine their position and function. According to this redefinition they have to develop implementation strategies.

\section{Saving land for the future}

In the future the Austrian communities close to Bratislava will be confronted with a big demand for building land. The past was characterised by contraction processes. The future will bring dynamic growth processes. To avoid irreversible erroneous trends, strategies have to be developed to save land for the future. It must be the aim to preserve space for recreation areas, ecologically valuable areas and good land for agriculture.

\section{Planning of economical activities according to the new situation}

In the future the economic structure of the Austrian communities will be influenced by Bratislava. Bratislava will be the community's "economical place«. The communities have to accept this new situation and according to their own interest develop strategies, how they can play a role in this economical place. It must be the aim to plan also according to the demands of the inhabitants of Bratislava. This is also relevant for the agriculture sector. The market for agricultural products will be in Bratislava. It must be also the aim to build stronger links between the already existing research institutes dealing with agriculture with research and education institutes in Bratislava. The communities have to develop a specific offer for different target groups, especially to service demands for recreation and leisure activities by the inhabitants of Bratislava.
Sustainable and integrated traffic solutions have to be found Because of the "Iron curtain « we have no integrated traffic infrastructure between Bratislava and the Austrian communities. Thus the present situation is completely incompetent in handling interaction between the city and the communities. In comparison to other agglomerations they are ironically in a quite good situation. They can learn from mistakes others have done in the past and find sustainable and integrated traffic solutions.

Especially for the public transport system it must be the aim to link the existing system in Bratislava with the surrounding communities in Austria.

\section{Demand for building land has to be recalculated}

The existing calculations of demand for building land in the communities don't reflect the new situation. Because the Slovak Republic joined the European Union it becomes more and more attractive for people from Bratislava to work in the city and to live in one of these small communities. The communities will be confronted with a big pressure by the market for building land. They have to adapt their master plans and set limits for building areas.

\section{The view of a place has to be protected}

The existing views on places are very important for the identity of these communities. Of course the view of a place is always changing. It is a normal process, which takes decades or even centuries. Hand in hand also the identity of a place will change. If this process goes to quickly, the identity of a place cannot develop. The results are places without meaning, without names, without character, which cannot be understood from outside. Because we can aspect a dynamic and quick development, protection of the view of the settlements will be an important task.

\section{Cooperation platforms have to be developed}

Finally the most important issue in this specific suburbanisation situation: Solutions to deal with this emerging question can only be found, if the communities and the city of Bratislava work together. Therefore efficient cooperation platforms have to be developed. This is a difficult task because in this specific situation we have to overcome borders between two different states with their own planning laws and planning cultures. We know how complex it is to deal with city-suburb relations even when the city and the surrounding communities are in one state.

As a result of the research project KOBRA (City-hinterland Co-operation Bratislava) the Austrian communities decided to develop together, a regional development concept for the area as the first step. This concept should be finalised in mid 2005. In the second step the concept should be discussed with the city planning authorities of Bratislava.

Univ. Ass. Dipl. Ing. Dr. techn. Thomas Dillinger, Institut für Städtebau und Raumplanung, Technische Universität Wien E-mail: tdilling@pop.tuwien.ac.at

\section{Notes}

[1] JORDES+, 2004

[2] Vienna-Bratislava Region, 2003, p. 122.

[3] ibid, p. 121

[4] ESPON 111, 2004, p. 11

[5] JORDES+, 2004, p. 27

[6] ibid, p. 18 
vol. 15, No. $2 / 04$

[7] ibid, p. 75-76

[8] ibid, p. 85

[9] ÖROK: Wirtschaftliche ..., 1997, p. 26.

[10] Veröffentlichungen der Akademie ..., 1976, S.2.

[11] Hamedinger, A., 1995.

[12] Prigge, W., 1998, p. 360.

[13] Institut für Landes- und Stadtentwicklungsforschung..., 1997, p. 128

[14] JORDES+, 2004, p. 85-88.

\section{Illustrations:}

Figure 1: Planning area (Source: $R C$ consulting, VITECC)

Figure 2: Protected areas in the region (Source: Institute of urban design and planning, UT Vienna)

Figure 3: Traffic situation/planning in the region (Source: Institute of urban design and planning, UT Vienna)

Figure 4: Development Perspectives (Source: Institute of urban design and planning, UT Vienna)

For sources and literature turn to page 38. 